\title{
Bilateral Vertebral Artery Dissection after a Chiropractic Therapy Session
}

\section{Dissecção bilateral das artérias vertebrais após sessão de quiropraxia}

\author{
Flavio Ramalho Romero ${ }^{1}$ Rodolfo Brum Vieira ${ }^{1}$ Carlos Clayton Macedo de Freitas ${ }^{1}$ \\ ${ }^{1}$ Universidade Estadual Paulista Júlio de Mesquita Filho, Medical \\ School, Campus de Botucatu, Botucatu, São Paulo, Brazil \\ Arq Bras Neurocir 2017;36:43-46.

\begin{abstract}
Address for correspondence Flavio Ramalho Romero, MD, MSc, PhD, Universidade Estadual Paulista Julio de Mesquita Filho, Faculdade de Medicina, Campus de Botucatu, Botucatu, São Paulo, Brazil (e-mail: frromero@ig.com.br).
\end{abstract}

\author{
Abstract \\ Keywords \\ - vertebral artery \\ dissection \\ - cervical manipulation \\ - stroke

\section{Resumo} \\ Palavras-chave \\ - dissecção das artérias \\ vertebrais \\ - manipulação cervical \\ - isquemia cerebral
}

Vertebral artery dissection (VAD) is a rare and sometimes unrecognized cause of stroke in patients younger than 45 years. Herein, we describe a very rare case of bilateral vertebral artery dissection after a session of cervical therapy manipulation (chiropractic).

Dissecção das artérias vertebrais (VAD) é uma causa de infarto rara e muitas vezes não identificada em pacientes com menos de 45 anos. Descrevemos um raro caso de dissecção bilateral das artérias vertebrais após sessão de quiropraxia.

\section{Introduction}

Vertebral artery dissection (VAD) is a rare and sometimes unrecognized cause of stroke in patients younger than 45 years. $^{1-3}$ Patients typically present with severe occipital headache and posterior nuchal pain following a recent head or neck injury; they also present a subsequent development of focal neurologic signs due to the ischemic lesion of the brainstem or cerebellum. ${ }^{4-7}$

The overall incidence of VAD is of $\sim 1-1.5$ per 100,000. Spontaneous VAD accounts for less than $1 \%$ of all ischemic strokes, but it is an important cause of ischemic stroke in young and middle-aged patients, accounting for $\sim 10 \%$ of such cases. ${ }^{8-10}$

received

September 30, 2016

accepted

December 2, 2016

published online

January 4, 2017 10.1055/s-0036-1597926. ISSN 0103-5355.
Herein, we describe a very rare case of bilateral vertebral artery dissection after a session of cervical therapy manipulation (chiropractic).

\section{Case}

A 32-year-old female patient presented at the Emergency Care Unit with severe headache, nauseas and vomiting, and somnolence. At neurological examination she had bilateral abducens nerve palsy and a Glasgow coma score of 9 points. Computed tomography (CT) images showed extensive right cerebellar ischemia with fourth ventricle and brainstem compression and supratentorial ventricular enlargement. Her family reported a medical visit three days after these

Copyright (e 2017 by Thieme Revinter Publicações Ltda, Rio de Janeiro, Brazil

\section{License terms}




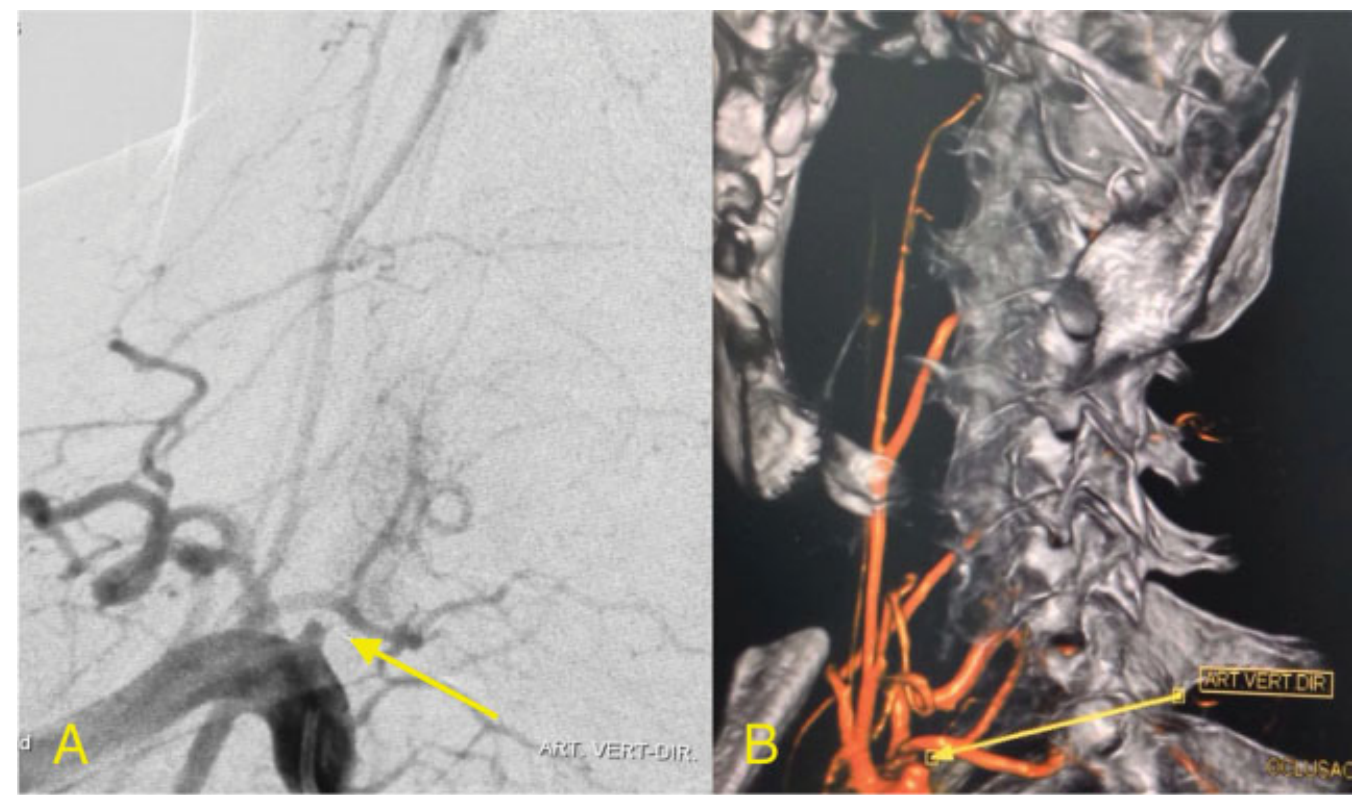

Fig. 1 (A) Initial angiography showing right vertebral artery dissection (yellow arrow). (B) Angiography reconstruction showing right vertebral artery dissection (yellow arrow).

events for a cervical pain that was extremely manipulated by this professional with strong lateral torsion.

Posterior cranial fossa decompression with external ventricular drain (EVD) was performed, and a four-intracranial vessel angiography was made. The initial angiography (- Figs. 1 and $\mathbf{2}$ ) showed bilateral vertebral artery occlusion in the intracranial portion at proximal cervical segments. Also, a good collateral circulation through the extracranial carotid artery branches and a posterior communicating artery was observed, providing good blood flow for most of the brainstem and cerebellum. So, a double antiplatelet therapy with acetylsalicylic acid and clopidogrel was initiated.

The patient had a good recovery of her neurological condition after the procedure, but the nystagmus and the dizziness remained. After three days, the EVD was removed, and CT images showed completely decompression of the fourth-ventricle. After six days, the patient was discharged for physical and neurological rehabilitation.

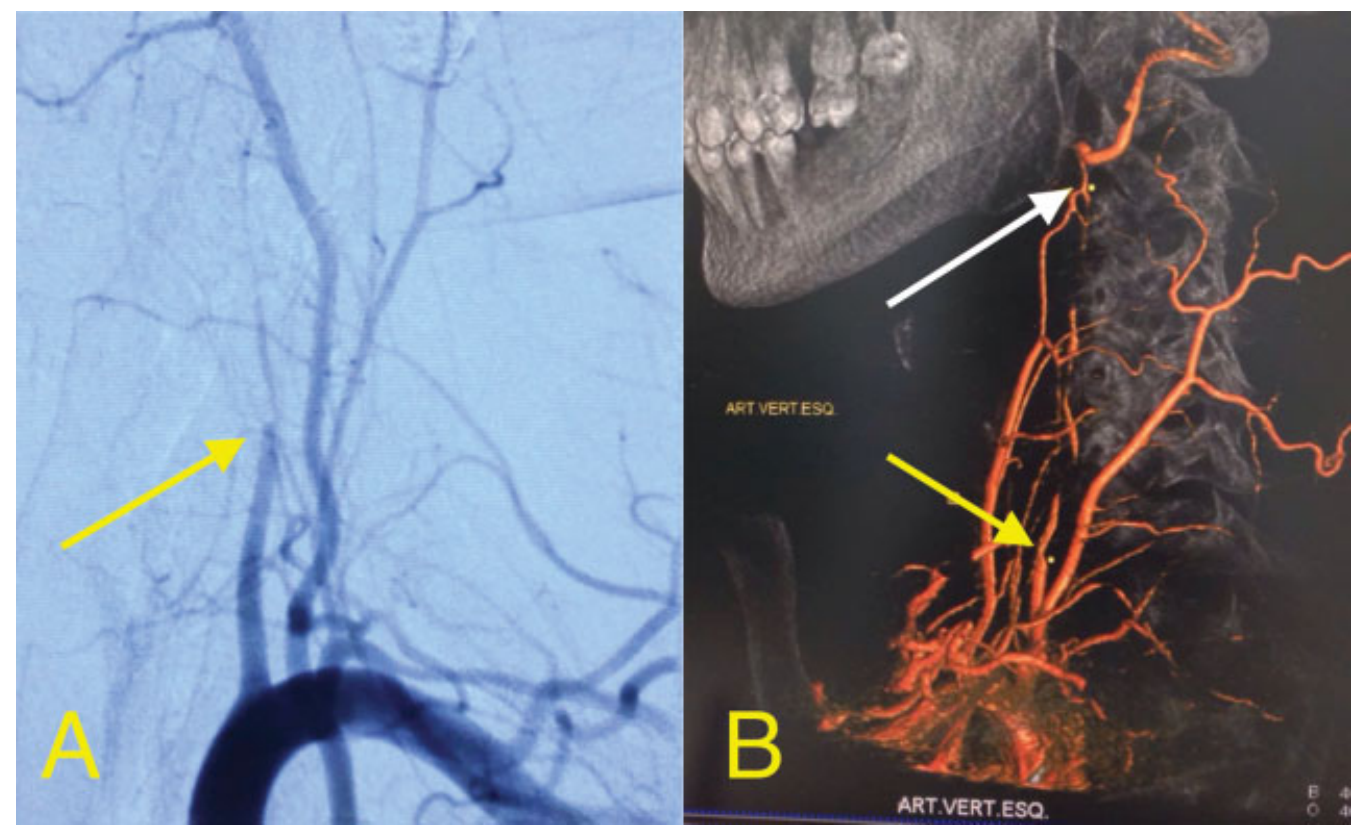

Fig. 2 (A) Initial angiography showing left vertebral artery dissection (yellow arrow). (B) Angiography reconstruction showing left vertebral artery dissection (yellow arrow). The white arrow shows the collateral circulation through the external carotid artery branches supplying irrigation for the left vertebral artery region. 


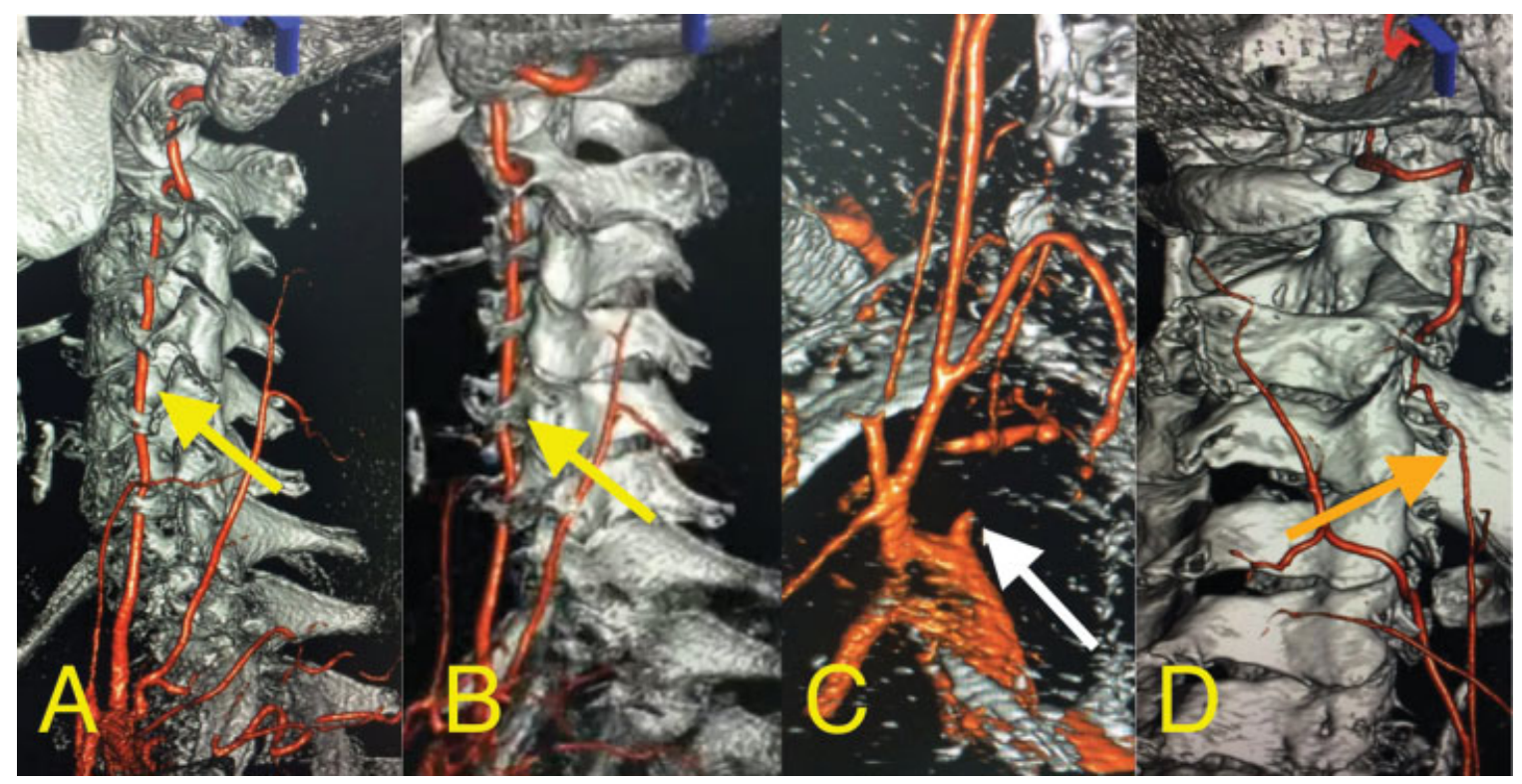

Fig. 3 Angiography reconstruction made 30 days after the first endovascular exam. (A and B) The yellow arrows show the left vertebral artery flow recovery. (C) The white arrow points to the right vertebral artery that remains without flow. (D) The orange arrow shows the collateral branches from the external carotid artery to the right vertebral artery region.

After 30 days, a new angiography was performed ( - Fig. 3), showing the right vertebral artery completely recovered and the left vertebral artery still without flow. At this moment, she was asymptomatic. After 90 days, the antiplatelet therapy was stopped, and she remained asymptomatic.

\section{Discussion}

Arterial dissection is a vascular injury characterized by a tear in the artery wall with the development of intramural hematoma. Consequently, a lumen stenosis or an aneurysmal dilatation of the artery may occur. In the past, it was thought to be a rare cause of stroke, particularly in the absence of trauma, and the diagnosis was usually not made until the postmortem examination. ${ }^{1,3-7}$

Neck trauma is strongly associated with extracranial VAD, because the vertebral artery is vulnerable to mechanical injury at $\mathrm{C} 1$ to $\mathrm{C} 2$ as it leaves the transverse foramen of the axis vertebra and suddenly turns to enter the intracranial cavity. ${ }^{8,11-13}$ The clinical manifestations include severe neck pain, mostly in the occipitocervical area followed after a variable interval by ischemic symptoms. In some patients there may not be any ischemic symptoms. Dizziness, vertigo, double vision, ataxia, and dysarthria are common clinical features. ${ }^{14-16}$ Lateral medullary (Wallenberg syndrome) and cerebellar infarctions are the most common types of strokes. Our patient manifested symptoms three days after a chiropractic therapy session, developing high intracranial pressure syndrome due to the closure of the fourth ventricle after right cerebellar ischemia. Besides both verteral arteries flow were interupted, a very rich collateral anastomotic circulation allowed blood flow for the brain stem and the left cerebellar hemisphere, avoiding a more severe manifestation. ${ }^{1,3,5-8,17-20}$

Several radiographic features suggest dissection, including the appearance of a flap, tapering stenosis or pseudoaneurysm on angiography, and the imaging of the arterial wall showing intramural blood. Catheter angiography has been the gold standard for the diagnosis of arterial dissections. ${ }^{21-24}$ The most common finding on angiography is the one called "string sign", a long segment of narrowed lumen. The pathognomonic features of dissection, such as an intimal flap or a double lumen, are found in less than $10 \%$ of cases. Artery may be tappered by occlusion of thr lumen, but sometimes aneurysmal dilatations are also founded. ${ }^{25-29}$

The choice of antiplatelet drug or anticoagulant drug was at the discretion of the local physician. Antiplatelet treatments included aspirin, dipyridamole, or clopidogrel alone or in combination. ${ }^{14,19-22}$ For patients assigned to anticoagulation, treatment with heparin (either unfractionated heparin or a therapeutic dose of low-molecular weight heparin) was followed by warfarin, aiming for an international normalized ratio of 2-3. Novel oral anticoagulants were not used. ${ }^{19-22}$ Some studies compared the antiplatelet and anticoagulant treatments for extra cranial carotid and vertebral artery dissection, showing that recurrent stroke at 3 months is rare, with no significant difference between the two treatments. ${ }^{14}$ Although more strokes occurred in the antiplatelet group than in the anticoagulant group, this difference was counterbalanced by one major subarachnoid hemorrhage in the anticoagulant group. ${ }^{19,21,22}$ We chose antiplatelet therapy, considering the risk of bleeding after surgical procedure.

The prognosis depends on many factors, but the severity of the neurological deficits at the time of presentation is directly related to the functional outcome. ${ }^{1,6,21}$ Most 
patients with extracranial dissection do remarkably well if they survive the initial crisis. About $88 \%$ of patients show complete clinical recovery at follow-up. However, the overall risk of death, recurrent transient ischemic attacks, or stroke is of $\sim 10 \%{ }^{21}$ Even though our patient had bilateral vertebral artery dissection, she had a good outcome because the collateral circulation supplied irrigation for the vertebral and basilar arteries territory.

\section{References}

1 Kim YK, Schulman S. Cervical artery dissection: pathology, epidemiology and management. Thromb Res 2009;123(6):810-821

2 Raupp SF, Jellema K, Sluzewski M, de Kort PL, Visser LH. Sudden unilateral deafness due to a right vertebral artery dissection. Neurology 2004;62(8):1442

3 Stahmer SA, Raps EC, Mines DI. Carotid and vertebral artery dissections. Emerg Med Clin North Am 1997;15(3):677-698

4 Lyrer PA, Brandt T, Metso TM, et al; Cervical Artery Dissection and Ischemic Stroke Patients (CADISP) Study Group. Clinical import of Horner syndrome in internal carotid and vertebral artery dissection. Neurology 2014;82(18):1653-1659

5 Saeed AB, Shuaib A, Al-Sulaiti G, Emery D. Vertebral artery dissection: warning symptoms, clinical features and prognosis in 26 patients. Can J Neurol Sci 2000;27(4):292-296

6 Provenzale JM, Sarikaya B. Comparison of test performance characteristics of MRI, MR angiography, and CT angiography in the diagnosis of carotid and vertebral artery dissection: a review of the medical literature. AJR Am J Roentgenol 2009;193(4): 1167-1174

7 Beletsky V, Nadareishvili Z, Lynch J, Shuaib A, Woolfenden A, Norris JW; Canadian Stroke Consortium. Cervical arterial dissection: time for a therapeutic trial? Stroke 2003;34(12):2856-2860

8 Norris JW, Beletsky V, Nadareishvili ZG; The Canadian Stroke Consortium. Sudden neck movement and cervical artery dissection. CMAJ 2000;163(1):38-40

9 Rubinstein SM, Peerdeman SM, van Tulder MW, Riphagen I, Haldeman S. A systematic review of the risk factors for cervical artery dissection. Stroke 2005;36(7):1575-1580

10 Jaffre A, Ruidavets JB, Calviere L, Viguier A, Ferrieres J, Larrue V. Risk factor profile by etiological subtype of ischemic stroke in the young. Clin Neurol Neurosurg 2014;120:78-83

11 Haldeman S, Kohlbeck FJ, McGregor M. Stroke, cerebral artery dissection, and cervical spine manipulation therapy. J Neurol 2002;249(8):1098-1104

12 Smith WS, Johnston SC, Skalabrin EJ, et al. Spinal manipulative therapy is an independent risk factor for vertebral artery dissection. Neurology 2003;60(9):1424-1428
13 Stevinson C, Honan W, Cooke B, Ernst E. Neurological complications of cervical spine manipulation. J R Soc Med 2001;94(3): 107-110

14 Markus HS, Hayter E, Levi C, Feldman A, Venables G, Norris J; CADISS trial investigators.Antiplatelet treatment compared with anticoagulation treatment for cervical artery dissection (CADISS): a randomised trial. Lancet Neurol 2015;14(4):361-367

15 Kennedy F, Lanfranconi S, Hicks C, et al; CADISS Investigators. Antiplatelets vs anticoagulation for dissection: CADISS nonrandomized arm and meta-analysis. Neurology 2012;79(7):686-689

16 Fukuhara K, Ogata T, Ouma S, et al. Impact of initial symptom for accurate diagnosis of vertebral artery dissection. Int J Stroke 2015;10(100, Suppl A100):30-33

17 Thomas LC, Rivett DA, Attia JR, Levi C. Risk factors and clinical presentation of cervical arterial dissection: preliminary results of a prospective case-control study. J Orthop Sports Phys Ther 2015; 45(7):503-511

18 Ben Hassen W, Machet A, Edjlali-Goujon M, et al. Imaging of cervical artery dissection. Diagn Interv Imaging 2014;95(12): 1151-1161

19 Lyrer P, Engelter S. Antithrombotic drugs for carotid artery dissection. Cochrane Database Syst Rev 2003;(3):CD000255

20 Mustanoja S, Metso TM, Putaala J, et al. Helsinki experience on nonvitamin $\mathrm{K}$ oral anticoagulants for treating cervical artery dissection. Brain Behav 2015;5(8):e00349

21 Hernández-Durán S, Ogilvy CS. Clinical outcomes of patients with vertebral artery dissection treated endovascularly: a meta-analysis. Neurosurg Rev 2014;37(4):569-577

22 Caprio FZ, Bernstein RA, Alberts MJ, et al. Efficacy and safety of novel oral anticoagulants in patients with cervical artery dissections. Cerebrovasc Dis 2014;38(4):247-253

23 Mokri B. Traumatic and spontaneous extracranial internal carotid artery dissections. J Neurol 1990;237(6):356-361

24 Ramphul N, Geary U. Caveats in the management and diagnosis of cerebellar infarct and vertebral artery dissection. Emerg Med J 2009;26(4):303-304

25 Rodallec MH, Marteau V, Gerber S, Desmottes L, Zins M. Craniocervical arterial dissection: spectrum of imaging findings and differential diagnosis. Radiographics 2008;28(6):1711-1728

26 Schievink WI. Spontaneous dissection of the carotid and vertebral arteries. N Engl J Med 2001;344(12):898-906

27 Sturzenegger M, Mattle HP, Rivoir A, Rihs F, Schmid C. Ultrasound findings in spontaneous extracranial vertebral artery dissection. Stroke 1993;24(12):1910-1921

28 Park MS, Albuquerque FC, Nanaszko M, et al. Critical assessment of complications associated with use of the Pipeline Embolization Device. J Neurointerv Surg 2015;7(9):652-659

29 Cohen JE, Gomori JM, Rajz G, Itshayek E, Eichel R, Leker RR. Urgent off-label use of the pipeline flow diverter stent in selected ischemic cerebrovascular conditions: thrombotic segments and tortuous arteries. J Neurointerv Surg 2015;7(9):671-675 